


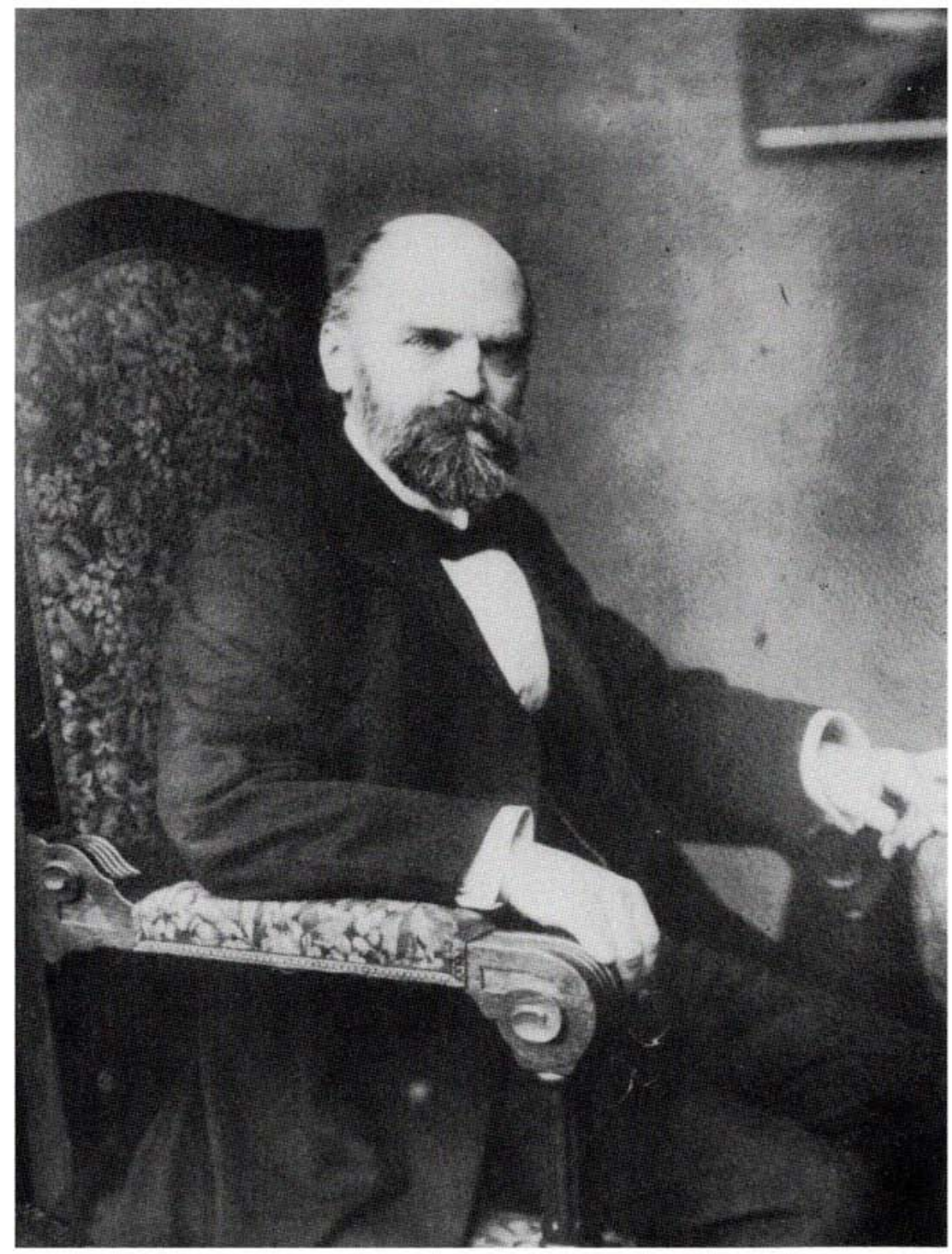

Professor Dr. Ferdinand Tönnies (1915)

(Bildarchiv Nissenhaus, Nordfriesisches Museum, Husum) 
Tönnies im Gespräch 2

Ferdinand Tönnies - Werkverzeichnis 


\section{Tönnies im Gespräch}

\section{Studien und Entwürfe}

Herausgegeben von

Prof. Dr. Alexander Deichsel

Institut für Soziologie, Universität Hamburg

Ferdinand-Tönnies-Arbeitsstelle

und

Prof. Dr. Lars Clausen

Institut für Soziologie, Christian-Albrechts-Universität zu Kiel

Tönnies Gesellschaft, Kiel

Im Verlag de Gruyter erscheint im Verlauf der nächsten Jahre die erste Gesamtausgabe der Werke Ferdinand Tönnies'.

„Tönnies im Gespräch" soll diese Werkedition mit Studienbänden und deutenden Entwürfen begleiten.

Am Klassiker Tönnies bilden sich auch heute diagnostische Köpfe und sozialwissenschaftliche Ratgeber. Ihre Beiträge sollen als Studien in die Entstehungszusammenhänge von Einzelwerken einführen; wie verwendbar die Ideen des Begründers der Soziologie in Deutschland sind, werden neue Entwürfe zeigen. 
Rolf Fechner

\title{
Ferdinand Tönnies
}

\author{
Werkverzeichnis
}

Walter de Gruyter · Berlin · New York 1992 
Quis leget haec?

Dr. Rolf Fechner ist Wissenschaftlicher Referent der Ferdinand-Tönnies-Gesellschaft e.V. zu Kiel, Herausgeber der Materialien der Ferdinand-Tönnies-Arbeitsstelle am Institut für Soziologie der Universität Hamburg sowie Mitherausgeber der Ferdinand-TönniesGesamtausgabe.

@ Gedruckt auf säurefreiem Papier, das die US-ANSI-Norm über Haltbarkeit erfüllt.

Die Deutsche Bibliothek - CIP-Einheitsaufnahme

Fechner, Rolf:

Ferdinand Tönnies : Werkverzeichnis / Rolf Fechner. - Berlin ;

New York : de Gruyter, 1992

(Tönnies im Gespräch ; 2)

ISBN 3-11-013519-1

NE: HST; GT

(C) Copyright 1992 by Walter de Gruyter \& Co., D-1000 Berlin 30.

Dieses Werk einschließlich aller seiner Teile ist urheberrechtlich geschützt. Jede Verwertung außerhalb der engen Grenzen des Urheberrechtsgesetzes ist ohne Zustimmung des Verlages unzulässig und strafbar. Das gilt insbesondere für Vervielfältigungen, Übersetzungen, Mikroverfilmungen und die Einspeicherung und Verarbeitung in elektronischen Systemen. Druck: WB-Druck GmbH, Rieden am Forggensee. - Bindearbeiten: Dieter Mikolai, Berlin. - Umschlagentwurf: Johannes Rother, Berlin. - Printed in Germany. 